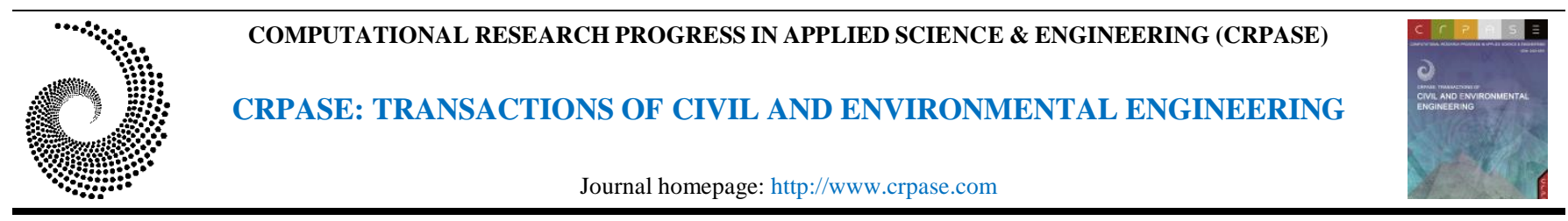

CRPASE: Transactions of Civil and Environmental Engineering 8 Article ID: 2225, 1-6, Special Issue: NCTT 2021

ISSN 2423-4591

Research Article

\title{
Analysis of Factors Associated with Traffic Injury Severity on Urban Roads in Different Lighting Conditions
}

\author{
Mohammad Rahmaninezhad Asil*, Hasti Toroghi, Iraj Bargegol \\ Department of Civil Engineering, Faculty of Engineering, University of Guilan, Rasht, Iran
}

\begin{tabular}{ll}
\hline Keywords & Abstract \\
\cline { 2 - 3 } $\begin{array}{l}\text { Light Condition, } \\
\text { Crash Severity, }\end{array}$ & $\begin{array}{l}\text { This research has studied the severity of vehicle-to-vehicle accidents in Rasht City in various } \\
\text { Urban Roads, }\end{array}$ \\
$\begin{array}{l}\text { Classification and } \\
\text { Regression Trees (CART), } \\
\text { Two-Vehicle Crashes. }\end{array}$ & $\begin{array}{l}\text { which is split into two classes of no injury and injury/death. The effects of independent } \\
\text { variables, including environmental, human, and roadway-related factors, on the vehicle-to- } \\
\text { vehicle accident severity, have been investigated. The classification and regression tree } \\
\text { (CART) method has been used for modeling purposes. The results showed that on daylight } \\
\text { accidents if the not-at-fault driver is a motorcycle, the accident tends to be fatal or injury } \\
\text { with the probability of } 95.6 \% \text {. At night with enough lighting, if the at-fault vehicle is a } \\
\text { motorcycle and the not-at-fault vehicle is not a motorcycle, there is a probability of } 72 \% \text { of } \\
\text { injury or death in case of inattention to the front. Also, if the accident reason is inattention } \\
\text { to the front and the not-at-fault driver is route familiar, there is a 95.1\% probability of injury } \\
\text { and death. In addition, at night accidents without enough lighting, if the not-at-fault vehicle } \\
\text { is a motorcycle and the accident does not occur in the summer, with the } 100 \% \text { probability, } \\
\text { the accident leads to injury and death. }\end{array}$ \\
\hline
\end{tabular}

\section{Introduction}

Traffic safety is of paramount importance when it comes to transportation because it can affect people's lives. Accidents kill an average of approximately 1.25 million people worldwide each year and cause substantial damage [1]. Also, since Iran is one of the most hazardous countries globally regarding the number of people who died in accidents per 100,000 population, studying the contributing factors of accidents in order to reduce their severity is vital. To reduce the rate of accidents and subsequently reduce the resulting mortality rate, it is necessary to investigate the factors affecting road accidents [2]. Factors affecting the accidents are primarily split into three general categories: road characteristics, vehicle characteristics, and human factors, each of which has different sub-sections $[3,4]$. One of the most important sub-sections in the category of road characteristics is the road lighting condition that has been studied in the literature of traffic safety. This factor is also very influential on the severity of accidents. In a study conducted in 2009 in Norway, it was found that the effect of lighting in reducing accidents at dusk is 2.3 times higher than its effect at nights [5]. Also, in a study conducted by Vanik in London in 2005, it was shown that although only 1.4 of trips will be made during the night (between $7 \mathrm{pm}$ and $8 \mathrm{am}$ ), $40 \%$ of death and injury of accidents occurred during this time. These results indicate that the lighting factor in the road, despite the lighter traffic flow at night, is so effective in the accident severity $[6,7]$. In addition, it can be the result that lighting can improve users' vision, specifically drivers of motor vehicles at night. As a result, the transportation system experiences fewer accidents. In a study conducted by Hafezi

\footnotetext{
* Corresponding Author: Mohammad Rahmaninezhad Asil

E-mail address: mo_rahmaninejad@msc.guilan.ac.ir
}

Received: 10 November 2021; Revised: 16 December 2021; Accepted: 11 January 2022

https://doi.org/10.52547/crpase.8.2225

\section{Academic Editor: Mahdi Feizbahr}

Please cite this article as: M.Rahmaninezhad Asil, H.Toroghi, I.Bargegol, Analysis of Factors Associated with Traffic Injury Severity on Urban Roads in Different Lighting Conditions, Computational Research Progress in Applied Science \& Engineering, CRPASE: Transactions of Civil and Environmental Engineering 8 (2022) 1-6, Article ID: 2225. 
et al. in Iran in 2020, it was shown that the presence of lighting on rural roads in the condition of foggy weather and also raise of lighting in urban roads reduces the number of collisions at night. This is because accidents during the night are more severe and more dangerous than accidents during the day. After all, darkness can affect drivers' attention [8], sight distance, and as a result, their proper maneuvering [9, 10]. Additionally, by studying the necessity of lighting conditions in the roads and intersections, the results reported a $25 \%$ reduction in the rate of accidents at night, $39 \%$ reduction in the number of accidents at night, and $31 \%$ reduction in accidents in the lighted intersections comparing their unlighted counterparts [11, 12]. Since many factors may influence the severity of the accidents, it is required to investigate the relationship in different scenarios [13]. The present research analyzed influential variables in three scenarios, including three lighting conditions while accidents happen (day and night with and without enough lighting).

\section{Methodology}

The decision tree is one of the machine learning methods that recently has been the prevalent tool in transportation analysis $[8,14]$. This method has appropriate application in the severity of the accident analysis. The classification and regression tree (CART) algorithm has been used to generate the decision trees in this research [8]. In the CART model's first stage, the input data are concentrated in the first node located at the top of the tree. Input data is split into branches based on the independent variables, which make the best homogeneity in each branch. The Gini index is used in this method, one of the best purity criteria so that the lowest value of the Gini coefficient causes the best splitting. The Gini index for the node $t$ is as below:

$$
\operatorname{Gini}(t)=1-\sum[P(j \mid t)]^{2}
$$

Where $P(j \mid t)$ is the relative frequency of $j$ class in the node $t$. By using the Gini coefficient, the data are split into the number of the child which derives from parents [14].

\section{Results}

\subsection{Descriptive Analysis Results}

In this research, the severity of vehicle-to-vehicle accidents has been modeled in three separate lighting scenarios, i.e., day and night with and without lighting, which has been investigated. The frequency of accidents in the study area based on lighting conditions (based on Rasht City urban traffic police database from 2015 to 2021 using KAM 114 forms) shows 7144, 2848, and 256 accidents for daylight and night with and without enough lighting, respectively. Due to the objective of this study, the target variable is the accident severity, a binary variable including two values of no injury or injury/fatal[15, 16]. The independent variables consist of 13 variables, including human, environmental, and road characteristics-related factors. Table 1 reports the frequency of crash severities by independent variables separately. The number of accidents based on month reported that the most and the least number of accidents were occurred in September and November, respectively. The reason for this can be the higher number of tourists who travel to Guilan province during these months. The accidents frequency during the days of the week shows that the least and the most accidents occurred on Friday and Saturday, respectively. This distribution indicates that on the weekend, the number of accidents decreased. Based on the accidents' statistics, the clear weather and dry pavement surface have the greatest casualties. Another factor under consideration is the collision angle according to which headon and side-impact accidents have the most fatalities. Another examined factor is the characteristics of the vehicle and driver. The frequency of vehicle types shows that the automobiles made in Iran and the motorcycles have the most injury and fatalities. The at-fault and not-at-fault driver's age specifications show that most accidents occurred for drivers aged 30 to 55 . The casualties are much more in men compared to women.

\subsection{Results of CART Method}

As previously stated, the models have split into three scenarios of accidents regarding variables' combination [14] on days and nights with and without lighting. The influential variables have been investigated in each of these three models.

\subsubsection{Accidents at Daylight}

According to longer hours and heavier traffic flow of days (because more land uses are active during the daylight hours) $[13,14]$ compared to nights, there are more accidents at daylights. In this research, 7144 accidents have been recorded, including 21 deaths and 3032 injuries. Figure 1 represents the result of the CART model. The results show that if the not-at-fault vehicle is a motorcycle, the accidents lead to injury or death with the probability of $95.6 \%$. Also, the results show that if the not-at-fault vehicle is a foreign company-made vehicle and the at-fault vehicle is a motorcycle, there is a $91.7 \%$ probability of injury or death. These results indicate that in the case of a motorcycle accident, if the vehicle is manufactured by a foreign company and the at-fault driver is unfamiliar, and their vehicle is Iranian-made, the accidents will be no-injury with the probability of $94.1 \%$. Also, the results show that if the collision angle is head-on, the at-fault vehicle is not a motorcycle, the vehicle is Iranian-made, and the not-at-fault vehicle is not a foreign company-made vehicle and motorcycle, the accident is no injury with the probability of $83.7 \%$.

Table 2 shows the prediction accuracy of the developed CART model. According to the prediction percentage, this model correctly predicts $97.3 \%$ and $57.9 \%$ of accidents, no injury and injury/fatal crashes, respectively. Also, the model's overall prediction accuracy was $80.5 \%$. 
Table 1. Description of variables

\begin{tabular}{|c|c|c|c|c|}
\hline \multirow[b]{2}{*}{ Variables } & \multirow[b]{2}{*}{ Category } & \multicolumn{2}{|c|}{ Accident severity } & \multirow[b]{2}{*}{ Total accidents } \\
\hline & & $\begin{array}{l}\text { No injury } \\
\text { accidents }\end{array}$ & $\begin{array}{l}\text { Injury/Fatal } \\
\text { accidents }\end{array}$ & \\
\hline \multirow[t]{7}{*}{ Day of week } & Saturday & 848 & 700 & 1548 \\
\hline & Sunday & 742 & 703 & 1445 \\
\hline & Monday & 835 & 637 & 1472 \\
\hline & Tuesday & 811 & 655 & 1466 \\
\hline & Wednesday & 817 & 715 & 1532 \\
\hline & Thursday & 884 & 688 & 1572 \\
\hline & Friday & 655 & 558 & 1213 \\
\hline \multirow[t]{4}{*}{ Season } & Spring & 1274 & 1290 & 2564 \\
\hline & Summer & 1399 & 1344 & 2743 \\
\hline & Fall & 1289 & 1060 & 2349 \\
\hline & Winter & 1630 & 962 & 2592 \\
\hline \multirow[t]{6}{*}{ Year } & 1394 & 569 & 856 & 1425 \\
\hline & 1395 & 645 & 668 & 1313 \\
\hline & 1396 & 596 & 834 & 1430 \\
\hline & 1397 & 1227 & 942 & 2169 \\
\hline & 1398 & 1195 & 540 & 1735 \\
\hline & 1399 & 1360 & 816 & 2176 \\
\hline \multirow[t]{4}{*}{ Angle } & Head-on & 561 & 755 & 1316 \\
\hline & Rear-end & 2101 & 1095 & 3196 \\
\hline & Side Swipe & 806 & 683 & 1489 \\
\hline & Side-Impact & 2124 & 2107 & 4231 \\
\hline \multirow[t]{2}{*}{ Surface Condition } & Dry & 4870 & 4203 & 9073 \\
\hline & Wet & 722 & 453 & 1175 \\
\hline \multirow[t]{4}{*}{ Weather Condition } & Clear & 280 & 423 & 703 \\
\hline & Cloudy & 4714 & 3877 & 8591 \\
\hline & Rainy & 575 & 348 & 923 \\
\hline & Snowy & 23 & 8 & 31 \\
\hline \multirow[t]{3}{*}{ Light condition } & daylight & 4091 & 3053 & 7144 \\
\hline & dark- lighted & 68 & 188 & 256 \\
\hline & dark-not-lighted & 1433 & 1415 & 2848 \\
\hline \multirow[t]{2}{*}{ At-Fault Driver } & Familiar & 3902 & 3934 & 7836 \\
\hline & Unfamiliar & 1690 & 722 & 2412 \\
\hline \multirow[t]{2}{*}{ Not At-Fault Driver } & Familiar & 3923 & 4107 & 8030 \\
\hline & Unfamiliar & 1299 & 432 & 1731 \\
\hline \multirow[t]{5}{*}{ At-Fault Vehicle (AFV) } & Passenger Car-made in Iran (PCIR) & 3468 & 3371 & 6839 \\
\hline & $\begin{array}{l}\text { Passenger Car-made in other countries } \\
\text { (PCOC) }\end{array}$ & 1273 & 486 & 1759 \\
\hline & Motorcycle & 64 & 540 & 604 \\
\hline & Pickup & 333 & 160 & 493 \\
\hline & Heavy Vehicle & 454 & 99 & 553 \\
\hline \multirow[t]{5}{*}{ Not At-Fault Vehicle (NAFV) } & Passenger Car - made in Iran (PCIR) & 3390 & 2068 & 5458 \\
\hline & Passenger Car - made in other countries & 1633 & 293 & 1926 \\
\hline & Motorcycle (PCOC) & 91 & 2099 & 2190 \\
\hline & Pickup & 259 & 111 & 370 \\
\hline & Heavy Vehicle & 219 & 85 & 304 \\
\hline \multirow[t]{3}{*}{ At-Fault Driver Age (AF Age) } & $<30$ & 1623 & 1371 & 2994 \\
\hline & $31-55$ & 3043 & 2079 & 5122 \\
\hline & $>56$ & 543 & 391 & 934 \\
\hline \multirow{3}{*}{$\begin{array}{l}\text { Not At-Fault Driver Age } \\
\text { (NAF Age) }\end{array}$} & $<30$ & 1454 & 1573 & 3027 \\
\hline & $31-55$ & 3135 & 1764 & 4899 \\
\hline & $>56$ & 489 & 327 & 816 \\
\hline \multirow[t]{2}{*}{ At-Fault Driver Gender } & Male & 4884 & 4128 & 9012 \\
\hline & Female & 708 & 528 & 1236 \\
\hline \multirow{2}{*}{ Not At-Fault Driver Gender } & Male & 4813 & 4323 & 9136 \\
\hline & Female & 778 & 333 & 1111 \\
\hline
\end{tabular}




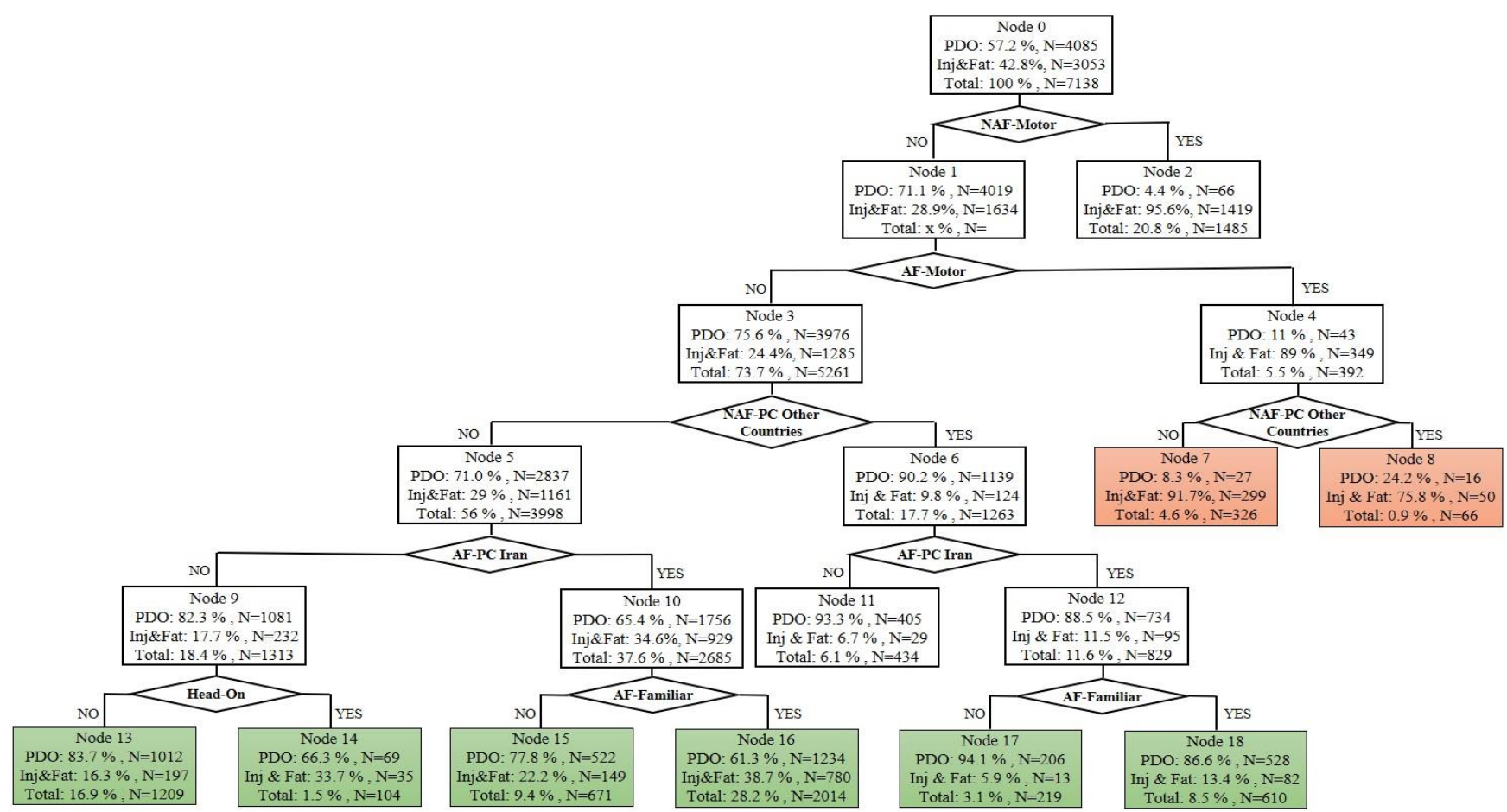

Figure 1. The results of the developed CART model for vehicle-to-vehicle crashes at daylight condition

Table 2. Prediction accuracy of the model developed for daylight condition

\begin{tabular}{|c|c|c|c|c|}
\hline \multirow[b]{3}{*}{ Observed } & & \multicolumn{3}{|c|}{ Predicted } \\
\hline & & \multicolumn{2}{|c|}{ Accidents severity } & \multirow{2}{*}{$\begin{array}{c}\text { Correct } \\
\text { percentage }\end{array}$} \\
\hline & & PDO & Injury \& Fatal & \\
\hline Accidents severity & PDO & 3976 & 109 & 97.3 \\
\hline & Injury \& Fatal & 1285 & 1768 & 57.9 \\
\hline Overall percentage & & 73.7 & 26.3 & 80.5 \\
\hline
\end{tabular}

\subsubsection{Accidents at Night with Lighting}

Urban roads in Rasht are often equipped with enough lighting due to their heavy traffic flow. Overall, 2848 accidents have occurred at night with lighting on urban roads of Rasht City, which have left 10 death and 1433 injuries. Figure 2 shows the results of the CART model for this scenario. According to the results, if the at-fault vehicle is a motorcycle and the not-at-fault is not a motorcycle, in the case of not paying attention to the front, there is a probability of $72 \%$ of death or injury. Also, if the reason for the accident is inattention to the front and the not-at-fault driver is rout familiar, there is a probability of $95.1 \%$ of injury and death. If the not-at-fault driver is unfamiliar, the likelihood of injury or death is $73.3 \%$. It can be deduced from the results that if the not-at-fault driver is familiar, there is a greater chance of injury and death, about $20 \%$. Also, the results show that if neither of at-fault and not-at-fault vehicles is not a motorcycle and a foreign company-made vehicle, in the case of a familiar at-fault driver, the accident leads to death with a probability of $50.6 \%$.

Table 3 shows the prediction accuracy of the developed model. According to the prediction accuracy, this model correctly predicts $68 \%$ and $78.4 \%$ of no injury and injury/fatal accidents, respectively. Also, in general, the model accuracy is $73.2 \%$.

\subsubsection{Accidents at night without lighting}

Considering that Rasht City is the capital of Guilan province, most of its roads have lighting. However, some of the roads do not have sufficient lighting, causing 256 accidents, of which 3 and 185 accidents have led to death and injury, respectively. Figure 3 shows the model created from the CART method. This research gives the possibility that if the not-at-fault driver is a motorcycle and the accident does not occur in summer, with a probability of $100 \%$, the accident leads to injury and death. Also, if the accident happens in summer, the likelihood of accidents leading to injury or death is $96.4 \%$. It can also be mentioned that if the at-fault and not-at-fault vehicles are not a motorcycle, and the collision angle is head-on, with a probability of $91.7 \%$, the accidents lead to injury or death.

Table 4 shows the percentage of the model prediction. According to the prediction percentage, this model correctly predicts $83.8 \%$ and $77.7 \%$ of no injury and injury/fatal accidents, respectively. Also, in general, the model accuracy is $79.3 \%$. 


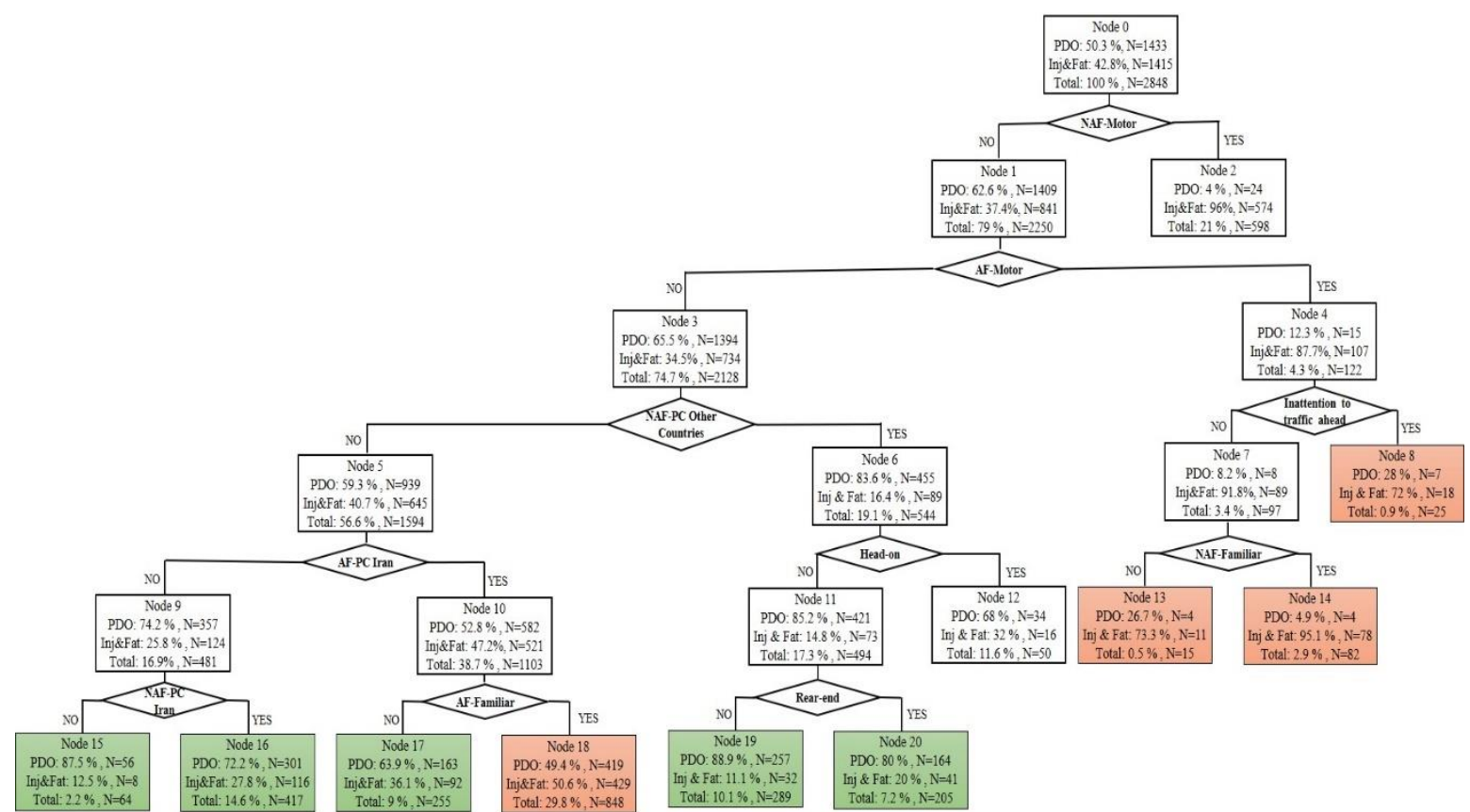

Figure 2. The results of the developed CART model for vehicle-to-vehicle crashes at night with enough lighting conditions.

Table 3. Prediction accuracy of the model developed for nights with enough lighting condition

\begin{tabular}{|c|c|c|c|c|}
\hline \multirow[b]{3}{*}{ Observed } & & \multicolumn{3}{|c|}{ Predicted } \\
\hline & & \multicolumn{2}{|c|}{ Accidents severity } & \multirow{2}{*}{$\begin{array}{c}\text { Correct } \\
\text { percentage }\end{array}$} \\
\hline & & PDO & Injury \& Fatal & \\
\hline Accidents severity & PDO & 975 & 458 & 68 \\
\hline & Injury \& Fatal & 305 & 1110 & 78.4 \\
\hline Overall percentage & & 44.9 & 55.1 & 73.2 \\
\hline
\end{tabular}

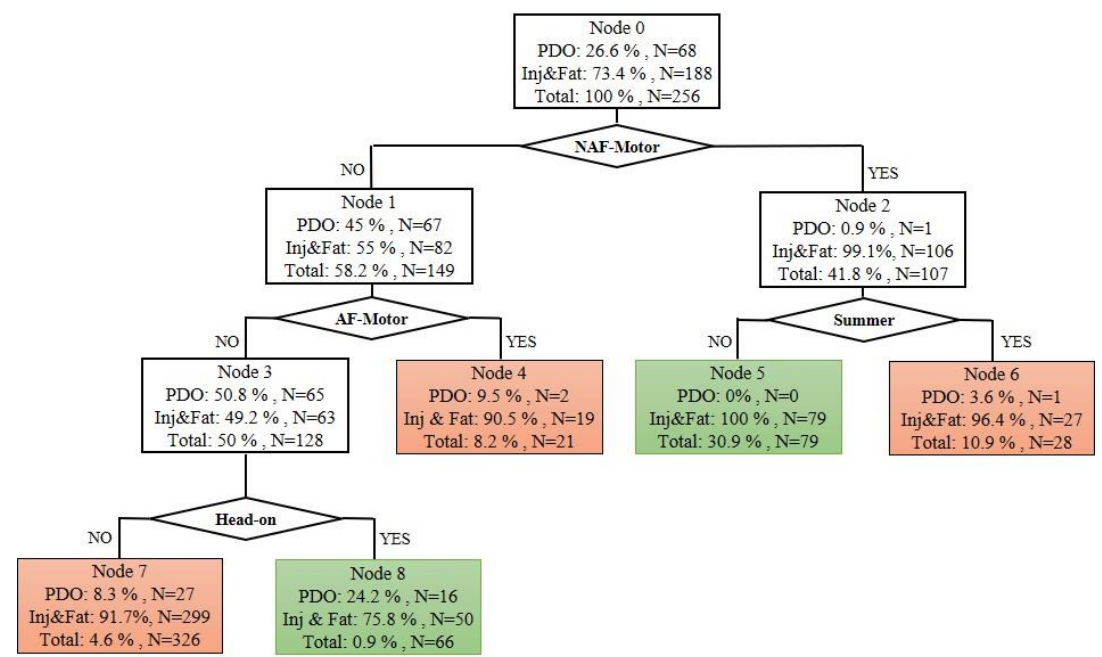

Figure 3. The results of the developed CART model for vehicle-to-vehicle crashes at night without lighting conditions.

Table 4. Prediction accuracy of the model developed for night without lighting condition

\begin{tabular}{|c|c|c|c|c|}
\hline \multirow[b]{3}{*}{ Observed } & & \multicolumn{3}{|c|}{ Predicted } \\
\hline & & \multicolumn{2}{|c|}{ Accidents severity } & \multirow{2}{*}{$\begin{array}{c}\text { Correct } \\
\text { percentage }\end{array}$} \\
\hline & & $\mathrm{PDO}$ & Injury \& Fatal & \\
\hline \multirow[t]{2}{*}{ Accidents severity } & PDO & 57 & 11 & 83.8 \\
\hline & Injury \& Fatal & 42 & 146 & 77.7 \\
\hline Overall percentage & & 38.7 & 61.3 & 79.3 \\
\hline
\end{tabular}




\subsection{Variables' Importance Across the Developed CARTs}

Table 5 shows the effective variables in developing CART models across the three scenarios of this study. Most results were somehow consistent between the two modeling approaches. In other words, all three models were able to identify somehow similar important predictors, which highlighted the similarity between these models' results. In all three models, motorcycles play a significant role in developing trees, whether at-fault or not-at-fault. On the other hand, for example, drivers' age was only influential when the crash occurred on a night without enough lighting. This can clearly indicate that unlighted streets at night are complicated driving situations, especially for inexperienced (young) drivers [17]. Overall, the results were primarily similar between daylight and lighted conditions at night; yet, they were both different with night crashes in unlighted situations.

Table 5. Importance rank of the variables under different lighting conditions.

\begin{tabular}{cccc}
\hline Rank & Daylight & Night with enough lighting & Night without lighting \\
\hline$(1)$ & NAF-Motorcycle & NAF-Motorcycle & NAF-Motorcycle \\
$(2)$ & AF-Motorcycle & AF-Motorcycle & NAF- Familiar \\
$(3)$ & NAF- PCOC & NAF- PCOC & AF-Motorcycle \\
$(4)$ & NAF-PCIR & NAF-PCIR & NAF-PCIR \\
$(5)$ & AF-PCIR & AF-PCIR & Head-On \\
$(6)$ & AF- Familiar & AF- PCOC & NAF Young (Age <30) \\
$(7)$ & AF- PCOC & Swerving & Fall \\
$(8)$ & Head-On & Loosing vehicle's control & Ignoring right of way \\
$(9)$ & Loosing vehicle's control & Head-On & Cloudy \\
$(10)$ & AF- Pickup & Inattention to traffic ahead & Deviation to left \\
$(11)$ & Deviation to left & Rear-End & Side-Swipe \\
\hline
\end{tabular}

\section{Conclusion}

The first step for controlling traffic deaths and injuries is finding influential factors. Yet, accidents' influential factors may play varying roles in different conditions. One of the most effective factors whose effect may greatly influence other factors in a crash is the lighting condition. This study aimed to investigate the factors affecting the severity of urban two-vehicle crashes in different lighting conditions [18]. Three scenarios, including the crashes that occurred at daylights, nights with enough lighting, and nights without lighting, were defined. Using the CART model, results showed that influential factors were mostly similar between daylight crashes and crashes that happened on lighted streets at night. However, dark streets at night were able to involve some other factors in the severity of twovehicle crashes [19].

Policymakers can consider the results of this study to prioritize the improvements needed to be made in different streets.

\section{References}

[1] World Health Organization, Road traffic injuries. (2020)

[2] M. Vahedi Saheli, M. Effati, Examining the impact of land-use related factors on rural traffic collisions. Journal of Injury and Violence Research 11 (2019).

[3] M. Effati, H. Behbahani, S. Mortezaei, M. Vahedi Saheli, Modelling and Analyzing the Severity of Two-Lane Highway Crashes Using the Spatial Data mining, Case Study: Old Corridor of Qazvin-Loshan. Journal of Civil and Environmental Engineering (2020).

[4] V. Najafi Moghaddam Gilani, S. M. Hosseinian, M. Ghasedi, M. Nikookar, Data-driven urban traffic accident analysis and prediction using logit and machine learning-based pattern recognition models. Mathematical problems in engineering (2021).

[5] P. O. Wanvik, Effects of road lighting: An analysis based on Dutch accident statistics 1987-2006. Accident Analysis \& Prevention 41 (2009) 123-128

[6] H. Ward, N. Shepherd, S. Robertson, M. Thomas, Night-Time Accidents: A Scoping Study. Report to the AA Motoring Trust and Rees Jeffreys Road Fund. (2005).

[7] I. Bargegol, V. N. M. Gilani, The effect of rainy weather on walking speed of pedestrians on sidewalks. Buletin Teknol Tanaman 12 (2015) 217-22.
[8] E. Abbasi, Y. Li, X. Wu, B. Craig, Using Classification and Regression Trees (CART) to Identify Factors Contributing to Vehicle Crash Severity in a Port City, International Journal of Transportation Systems 6 (2021) 29-38.

[9] A. Hafezi, H. R. Behnood, A. Abdi, Safety effectiveness evaluation of road lighting projects in rural roadways. Quarterly Journal of Transportation Engineering (2020)

[10] S. M. Hosseinian, V. N. M. Gilani, Analysis of factors affecting urban road accidents in rasht metropolis. Eng Transactions 1 (2020) 1-4.

[11] R. Schwab, N. Walton, J. Mounce, M. Rosenbaum, Synthesis of safety research related to traffic control and roadway elements-Volume 2, Chapter 12: Highway Lighting. Report No. Fhwa-Ts-82233. Federal Highway Administration (1982).

[12] H. N. Isebrands, S. L. Hallmark, Z. Hans, T. McDonald, H. Preston, R. Storm, Safety impacts of street lighting at isolated rural intersections-part II, 2006.

[13] M. Vahedi Saheli, M. Effati, Segment-Based Count Regression Geospatial Modeling of the Effect of Roadside Land Uses on Pedestrian Crash Frequency in Rural Roads. International Journal of Intelligent Transportation Systems Research 19 (2021) 347-365.

[14] M. Effati, M. Vahedi Saheli, Examining the influence of rural land uses and accessibility-related factors to estimate pedestrian safety: The use of GIS and machine learning techniques. International Journal of Transportation Science and Technology (2021).

[15] M. Vahedi Saheli, M. Effati, Investigation of factors contributing to pedestrian crash severity in rural roads. Journal of Injury and Violence Research 11 (2019).

[16] M. Ghasedi, M. Sarfjoo, I. Bargegol, Prediction and analysis of the severity and number of suburban accidents using logit model, factor analysis and machine learning: a case study in a developing country. SN Applied Sciences 3 (2021) 1-16.

[17] M. Koloushani, M. Ghorbanzadeh, E. E. Ozguven, M. B. Ulak, Crash patterns in the CoViD-19 pandemic: the tale of four Florida counties. Future transportation 1 (2021) 414-442.

[18] S. Pourfalatoun, E. E. Miller, User perceptions of automated TruckMounted attenuators: Implications on work zone safety. Traffic injury prevention (2021) 1-8.

[19] B. Dimitrijevic, S. D. Khales, R. Asadi, J. Lee, Short-Term SegmentLevel Crash Risk Prediction Using Advanced Data Modeling with Proactive and Reactive Crash Data. Applied Sciences 12 (2022) 856. 